\title{
3651
}

\section{Use of News Stories as Case Studies for Teaching Engineering Analysis}

\author{
Ramesh C. Chawla \\ Department of Chemical Engineering, Howard University, Washington, DC 20059 \\ Chawla@scs.howard.edu
}

\begin{abstract}
Freshman engineering students take a two-course sequence of Introduction to Engineering courses in their first two semesters. The first course is a general course common to all disciplines and the second course is discipline-specific.

In the first course, the students are introduced to various topics including career options in various engineering fields, communication skills, ethics, intellectual property, problem solving, critical thinking and time management. Team projects (paper design and design $\&$ build) are a major part of the course. In the second course of the introductory sequence, chemical engineering students are exposed to chemical process design from an overall standpoint. Techniques of process synthesis and analysis are used to develop critical thinking skills for comparative analysis of potential alternatives. In addition to teaching elementary principles of various chemical engineering fundamentals, situations dealing with the importance of safety, ethics, economics and environmental issues are frequently incorporated in the design process. Current news stories provide a valuable resource as case studies for developing analytical skills in these areas.
\end{abstract}

Some of the recent examples of case studies based on news stories include overturning of a truck carrying chemical waste on the Capitol Beltway, high lead concentrations in the Washington, DC drinking water supply, and a chemical train explosion in Iran.

The students are assigned a homework assignment or a mini project to answer specific questions/objectives on the news story. A class discussion, after the submission of assignments, drives home the intricate points of analysis, along with potential extensions of the original physical situation. The case studies also provide an opportunity to introduce or review some of the related underlying principles in class, before the assignment is due. When presented in applied context related to real life situations, the students are more interested in learning the concepts.

These case studies have proved to be an interesting and informative tool in teaching the importance of ethics, safety, economics and environment to engineering problem solving. The depth and breadth of technical analysis can be adjusted to the level of the class from freshmen to seniors. In this paper, examples of these case studies and use of this approach in teaching engineering analysis will be presented. 


\section{Background}

Most universities have introductory courses for freshman engineering students that focus on the language of engineering, problem solving techniques, and basic concepts and fundamentals of the discipline. These techniques and the basic knowledge would then be required for more challenging and complex engineering problems during the next four to five years of engineering education. We have found that introducing comprehensive concepts through news stories of actual events, related to safety, chemical accidents and environmental disasters offer good comprehensive problems for engineering analysis, and create a more engaging and interesting learning style from the student's perspective.

Chemical engineering students are exposed to process analysis and synthesis in several courses. In general, concepts of mass and energy balances, heat transfer, fluid mechanics, kinetics, thermodynamics, and separation processes are integrated into a defined process design problem for the production of a chemical or product. In this paper, use of actual events, as reported in the news stories is discussed for the application of chemical engineering analysis. Four recent events in the news were used as examples. They include: (i) an overturned truck, carrying gasoline on a major highway, (ii) high occurrence of lead in the drinking water of a major city, and (iii) accident of a train, carrying chemicals. This source of real life problems provides a continuous supply of engineering analysis projects for chemical, mechanical, civil and environmental engineering disciplines. The first two are described in this paper.

The focus is to develop critical thinking skills in logical processing steps, coupled with simple mass and energy balances and economics. The physical situation is explained, objectives clearly defined, and relevant questions are formulated to develop an approach to develop a model of the physical situation. The students work in groups of three to four for about one to two weeks, and are required to make oral presentations and submit written reports for their projects.

\section{Media Reported Case Studies Examples}

I. Find and examine media articles on a chemical spill that occurred recently on a major highway. Write a report on the media's treatment of the spill and develop a mathematical model that describes how you would approach and solve this problem as a chemical engineer.

A sample solution of students' report is summarized in Tables 1-3, and a picture of an overturned tanker is shown in Figure 1. 


\section{Table 1: Summary of Two Chemical Spills from Media Reports}

After examining two newspaper reports on separate gasoline spills that occurred in Maryland and Washington State, we have put together a scenario that will describe the physical situation for which we will perform the analysis.

\section{Chemical Spill in Maryland}

-Location: I-95 in Laurel MD

- Time : $\quad 3: 30 \mathrm{pm}$, Monday $19^{\text {th }}$ February 2001

i. The report was found in the METRO section of the Washington Post (Tuesday, Feb 20, 2001).

ii. The local reporter recounted the accident giving details about the time and location of the spill.

iii. The report was written in basic layman terms targeted at the average reader, there were no chemical terms used and it was void of details of the actual method of the cleanup effort.

\section{Chemical Spill in Washington State}

-Location: $\quad$ Highway 101

-Time : $\quad$ 6:00pm, Sunday, July 2, 2000

-FUEL COMPANY: Pettit Oil Fuel

i. The report was found on the Department of Ecology's website.

ii. The oil spill was two fold in that it was on land as well as in the marshlands.

iii. As much as 1,500 gallons of the gasoline went into the salty marshlands of Jorgenson Slough.

iv. The owner of Pettit Oil Co. blames the accident on a maintenance problem with the truck's suspension.

v. Some of the gasoline was recovered with absorbent pads, and by a vacuum truck.

vi. The report was written in basic layman terms targeted at the average reader, there were no chemical terms used and it was void of details of the actual method of the cleanup effort.

Based on these media reports, the students formulated a problem and carried out the engineering analysis. The preliminary engineering analysis of a chemical spill is listed in Table 2. The extent of model development and treatment alternatives and analysis vary with the level of students (freshmen to seniors). Table 3 lists the components of engineering analysis of a chemical spill. 


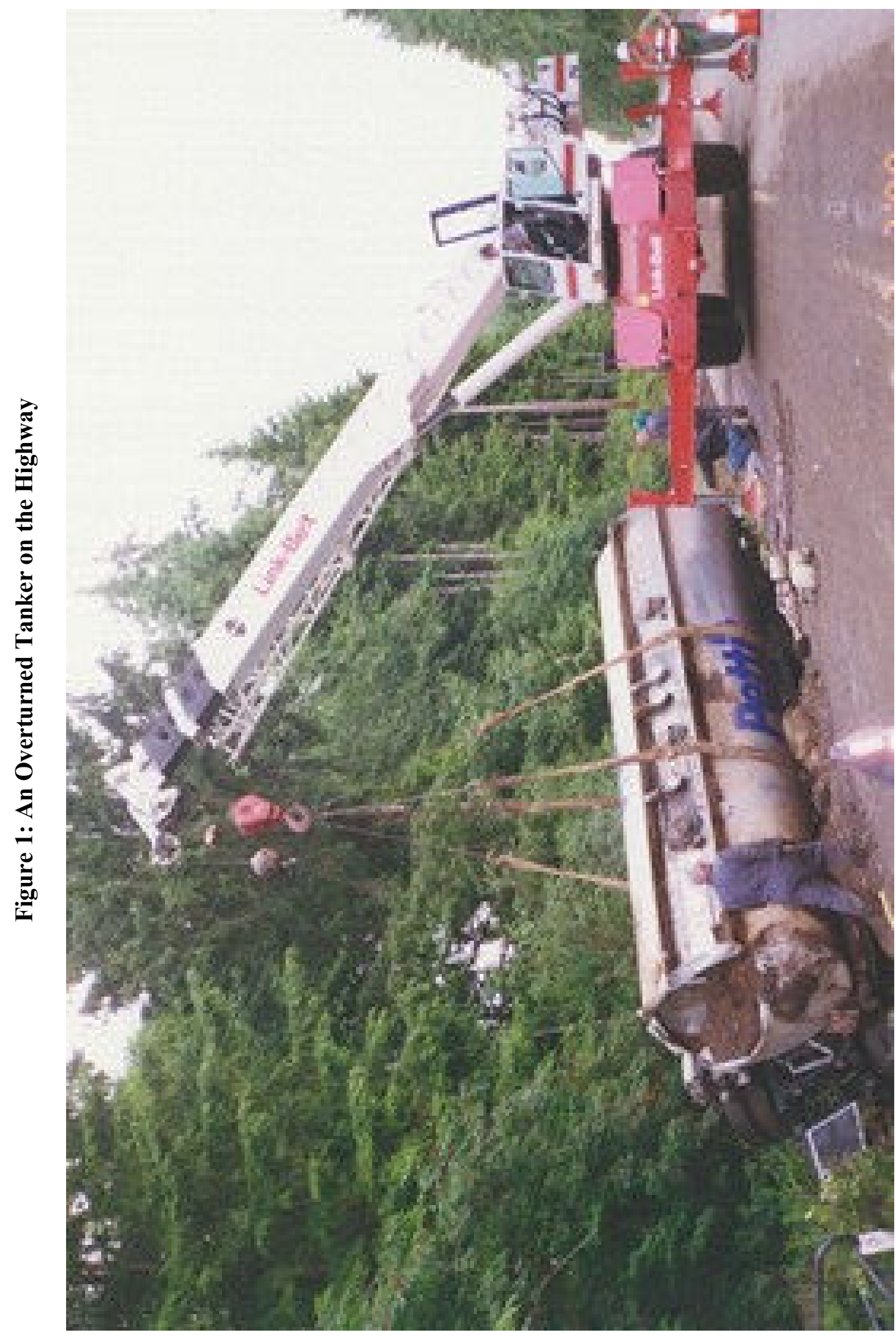

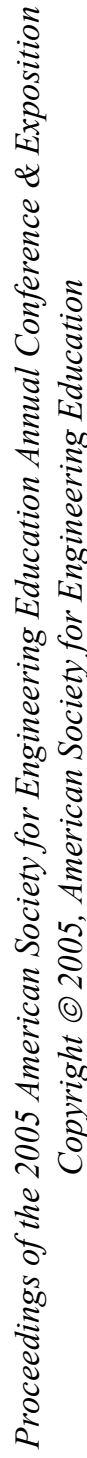

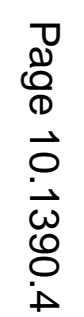



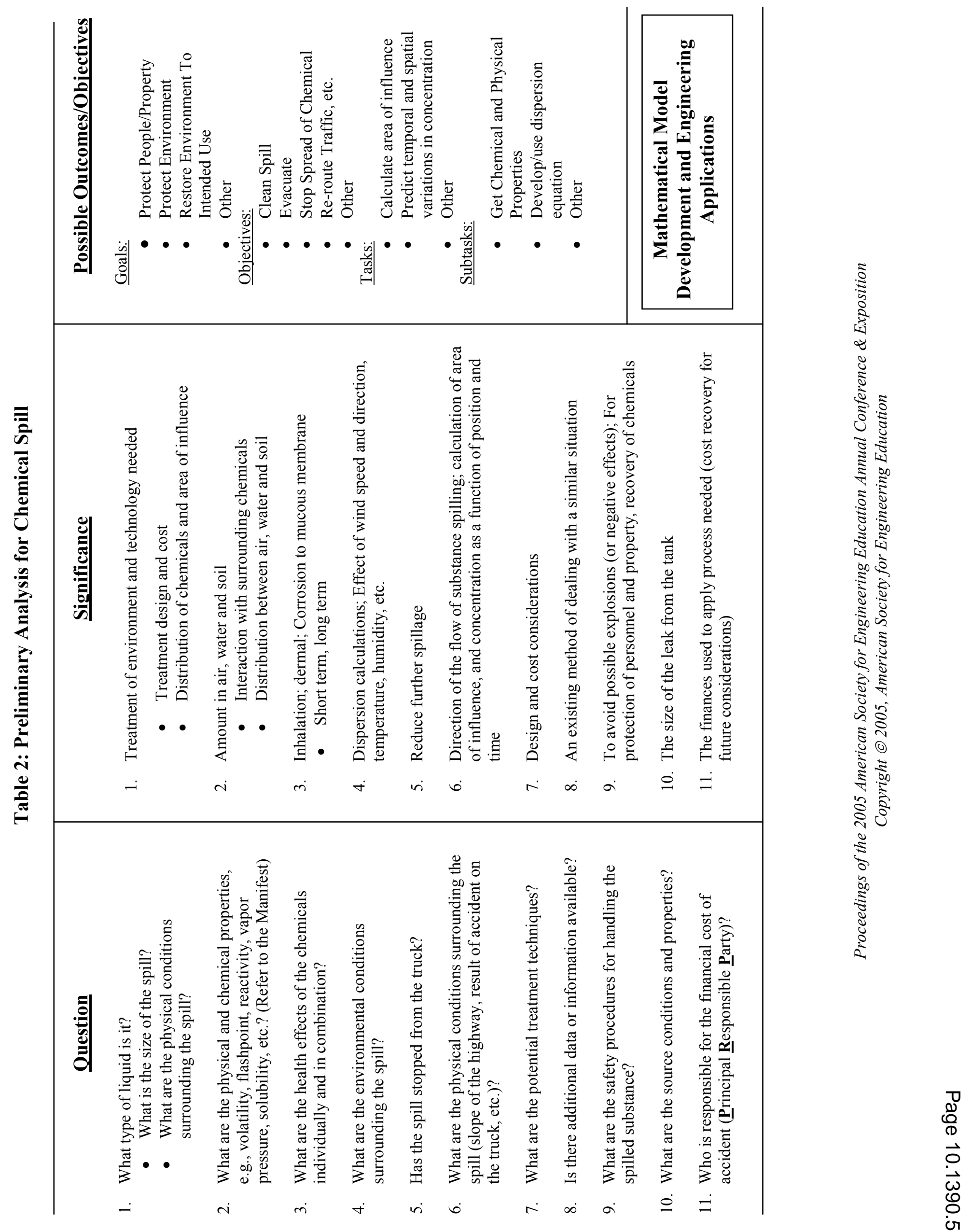
Table 3: Components of Engineering Analysis of a Chemical Spill.

\section{Physical Situation}

- A fuel truck overturned on a major highway, spilling 2000 gallons of the gasoline it was carrying, causing the traffic to slow for several hours. The accident occurred during rush hour and fuel leaked from the overturned tanker onto the roadway causing the fire department to close the ramps that led to the highway.

- The spilled gasoline collected in puddles on the roadway and in the drains on the roadside, before the cleanup effort was begun by the state's HAZMAT crew and the fire department. Fuel from the overturned tanker was eventually transferred into a second truck sent onsite by the fuel company.

\section{List of Outcomes/ Model objectives}

- Rapidly and efficiently restore regular traffic flow on the highway and connecting roads.

- Develop a mathematical model that would facilitate the engineering analysis of the problem for the short run and long term.

\section{Formulation of Questions for the Development of Mathematical Models}

1. What type of liquid is it? What is the size (volume) of the spill?

2. What are the physical and chemical properties, including volatility, vapor pressure, flashpoint, reactivity, solubility, etc.? (Refer to the Manifest)

3. Are there any health affects due to the spill?

4. What are the environmental conditions surrounding the spill?

5. Has the substance stopped leaking from the truck?

6. What are the physical conditions surrounding the spill (slope of the highway, result of accident on the truck, etc.)?

7. What are the treatment techniques: physical, chemical, thermal, innovative?

8. Are there any additional data or information available?

9. Are there any historical solutions to similar problems?

10. What are the safety procedures for handling the spilled substance?

11. What are the source conditions and properties?

12. Who is responsible for the financial cost of accident (Principal Responsible $\underline{\text { Party)}}$ ?

\section{Mathematical Model Development}

\section{Treatment Techniques: Timeline, Efficiency and Cost}

\section{Economics}

\section{Bibliography}


II. Perform engineering analysis on the recent problem of excessive levels of lead in the District of Columbia drinking water, and evaluate a treatment technique.

Table 4: Problem Statement \& Background of Lead in Drinking Water in Washington, DC

\begin{tabular}{|l|}
\hline Problem Statement \\
\hline - \\
- Lead levels in DC water became an issue of public concern in 2002 \\
- For the purpose of this project we have used solvent extraction for removal of lead from \\
water and we recommend that Calcium hydroxide be used to coat the pipes.
\end{tabular}

\section{Background}

- Lead, a metal found in natural deposits, is commonly used in household plumbing materials and water service lines.

- Sources of lead in water include leaching from service line pipes, faucets or fittings of brass in homes but can also be found in paints.

- Stipulation that change of water disinfectant from chlorine to chloroamine has caused more corrosion in pipes.

- The standard and acceptable level of lead in water was $50 \mathrm{ppb}$ but was adjusted to 15 ppb in the light of new health and exposure data.

- If not detected early, children with high levels of lead in their bodies can suffer from:

- Damage to the brain and nervous system

- Behavior and learning problems (such as hyperactivity)

- Slowed growth

- Hearing problems and Headaches

- Lead is also harmful to adults. Adults can suffer from:

$\circ$ Difficulties during pregnancy

- Other reproductive problems (in both men and women)

- High blood pressure

$\circ$ Digestive problems

- Nerve disorders, and memory and concentration problems

- Muscle and joint pain

- Lead binds to the soil and soil sediment in water, causing it to be poisonous

- Lead can also accumulate in some shell fish like mussels

- DC WASA plans to replace all the city's 23,000 lead pipes by 2010 at a cost of $\$ 300$ million. Homeowners wishing to replace the line into the residence can pay WASA contractors $\$ 100$ per linear foot and $\$ 500$ to run pipe through the wall into the home. The net cost is expected to increase by $5 \%$ in water bills averaging $\$ 22$ more annually. 
The chemical engineering analysis of the solvent extraction treatment technique was carried out and shown in Table 5 and Figures 2 and 3. Recommendations and conclusions are summarized in Table 6.

Table 5: Solvent Extraction Treatment for Lead in Drinking Water in Washington, DC

- Application of theory for mass transfer in isothermal two-phase system.

- Solvent extraction used to remove solid, soluble lead from water using a solvent (Solvent X)

- The identity of Solvent X to be later determined by further investigation.

- Calcium hydroxide will later be used to prevent further corrosion of pipes.

\section{Figure 2: Process Flow Sheet for Solvent Extraction of Lead from Water}

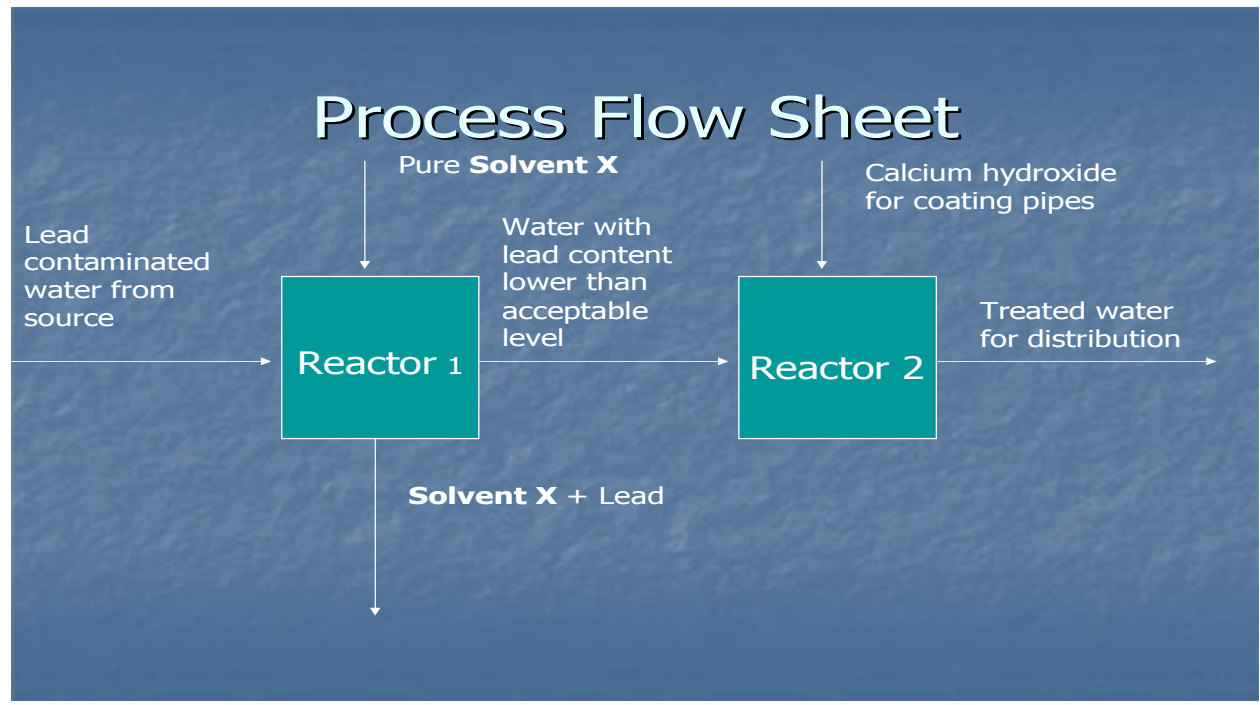

Figure 3: Calculation Diagram Shell for Solvent Extraction of Lead from Water

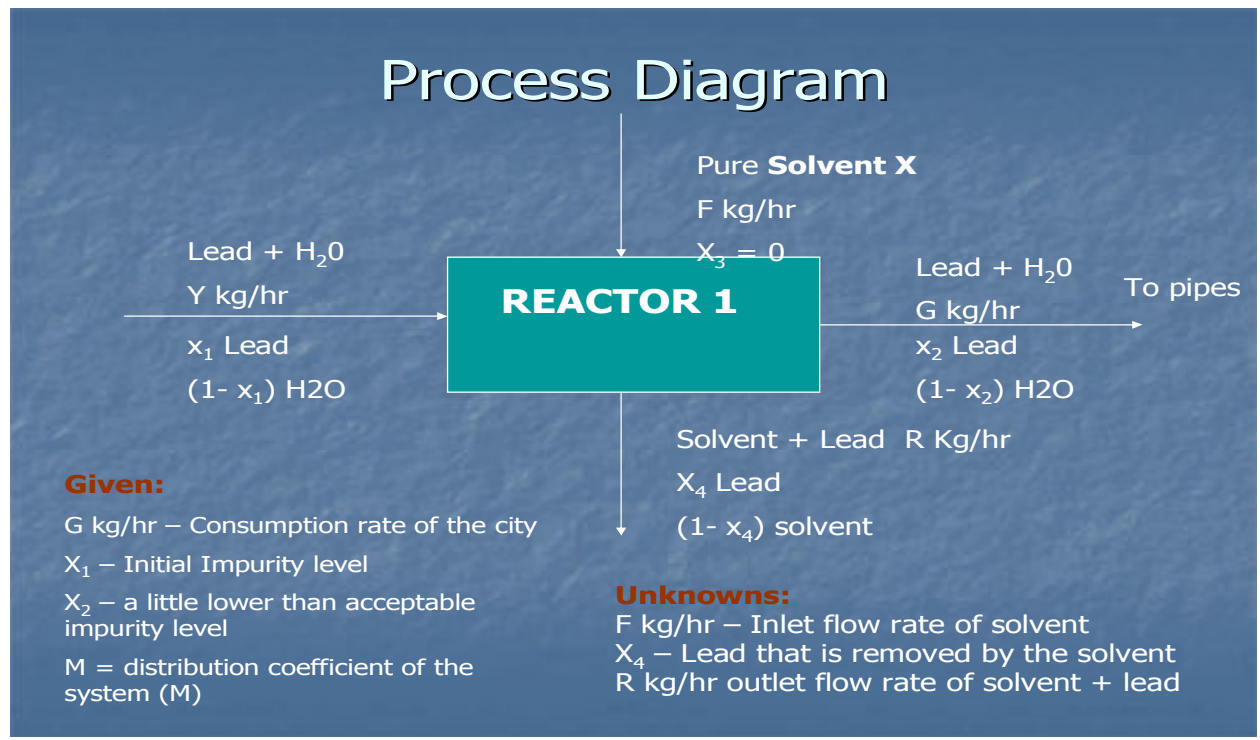

Proceedings of the 2005 American Society for Engineering Education Annual Conference \& Exposition Copyright (C) 2005, American Society for Engineering Education 
Table 6: Recommendations and Conclusions for treatment of Lead in Drinking Water

\section{Recommendations}

- Use of calcium hydroxide to reduce the lead in reservoirs

- Use of zinc orthophosphate to coat lead pipes thereby reducing corrosion

- Complete overhaul of existing lead pipes

\section{Conclusions}

- Lead in drinking water has various adverse effects on people, the economy and the environment.

- The ultimate and best solution would be to ban the use of lead based pipes and to provide suitable alternatives like PVC.

\section{Summary}

Everyday real life situations present potential for case studies. The physical situation and effects are generally reported in the media. These reports are written for lay public and are easy to comprehend. These situations can be expanded to probe further into the causes and remedies of the problems, while utilizing the concepts and fundamentals of science and engineering. It is an interesting teaching tool and students can relate to the practical aspects of engineering in everyday life.

\section{References}

1. Castaneda, Ruben, The Washington Post, Page B2, Tuesday, Feb 20, 2001.

2. HI Point Industries - Oclansorb http://www.oclansorb.com/oclan.htm

3. ABTEK - Technologies and Services http://www.bbriefings.com/pdf/30/exp032_t_absorb.pdf

4. EC-2100P http://www.ecochem.com/t_2100p.html

5. http://www.epa.gov/safewater/lead/

6. http://washingtonaqueduct.usace.army.mil/treatment_process.htm

7. http://www.washingtonpost.com

8. http://www.mwcog.org/environment/water/watersupply/lead

9. http://www.purewater.com 


\section{Acknowledgement}

I am thankful to the students in my Introduction to Engineering Design II and Chemical Engineering Analysis courses over the past several years for providing stimulus and reports for this paper.

\section{BIOGRAPHICAL INFORMATION}

Dr. RAMESH C. CHAWLA is a professor of chemical engineering at Howard University. He has over thirty years of experience in teaching, research and industrial consulting in the fields of chemical and environmental engineering. His research and teaching interests include reaction engineering, separation processes, environmental engineering, and physical, chemical and biological treatment of hazardous wastes. 